\title{
Adolescents' selfie-taking and selfie-editing: A revision of the photo manipulation scale and a moderated mediation model
}

\author{
Francesca Gioia $^{1}$ • Siân McLean ${ }^{2} \cdot$ Mark D. Griffiths $^{3} \cdot$ Valentina Boursier $^{1}$ (D)
}

Accepted: 31 March 2021 / Published online: 10 April 2021

(C) The Author(s) 2021

\begin{abstract}
'Selfie practices' (e.g., editing, filtering, sharing) have become adolescents' daily behaviors. The increasing centrality of online visual self-presentation might increase adolescents' appearance-related concerns, problematic monitoring, and photo manipulation (PM). However, few studies focused on body image control in photos (BICP) and PM, and no studies evaluated the influence of selfie-expectancies on photo-taking and photo-editing. Consequently, two studies were conducted. Study1 psychometrically evaluated the PM scale $(N=1353)$. Study2 evaluated the mediating role of BICP and the moderating role of gender in the relationship between selfie-expectancies and PM $(N=453)$. The revised PM scale showed good psychometric properties. BICP mediated the relationship between selfie-expectancies and PM and being male significantly affected the relationship between the variables. Implications for adolescents' appearance-related issues are discussed.
\end{abstract}

Keywords Selfie practice $\cdot$ Social media $\cdot$ Body image $\cdot$ Photo manipulation $\cdot$ Adolescence

\section{Introduction}

In contemporary society, web-based communication via social networking sites (SNSs) represents a widespread daily activity, especially among adolescents and young adults (e.g., Boursier \& Manna, 2018a, 2018b; D’Arienzo et al., 2019; Gioia \& Boursier, 2019b; Kırcaburun et al., 2019; Kuss \& Griffiths, 2017). In early 2021, there were more than 4.2 billion active social media users (We Are Social, 2021) and teenagers comprised a high percentage of this total. More specifically, high proportions of adolescents aged 13 to

Valentina Boursier

valentina.boursier@unina.it

Francesca Gioia

francesca.gioia@unina.it

Siân McLean

s.mclean@latrobe.edu.au

Mark D. Griffiths

mark.griffiths@ntu.ac.uk

1 Department of Humanities, University of Naples Federico II, Via Porta di Massa, 1 -, 80133 Naples, Italy

2 School of Psychology and Public Health, La Trobe University, Melbourne, Victoria, Australia

3 International Gaming Research Unit, Psychology Department, Nottingham Trent University, Nottingham, UK
14 years (79\%) and 15 to 17 years $(84 \%)$ had active social media profiles (Mascheroni \& Ólafsson, 2018) suggesting that social media is pivotal in adolescents' social interactions and leisure activities (Bryant \& Bryant, 2005; Musetti et al., 2020). A key feature of the online platforms favored by adolescents is the highly visual nature of the interactions those platforms afford. According to recent findings, SNSs appear to promote increasing amounts of digital visual content (Feltman \& Szymanski, 2018), transforming contemporary everyday life to a "more photographic" life (d'Aloia \& Parisi, 2016; p. 3) in which editing, filtering, posting, sharing, tagging, and commenting have become natural daily behaviors (d'Aloia \& Parisi, 2016; Fox \& Vendemia, 2016). In this regard, selfie-taking and selfie-sharing constitute two of the most popular activities carried out on SNSs (Balakrishnan \& Griffiths, 2018; Diefenbach \& Christoforakos, 2017; Fox \& Vendemia, 2016; Katz \& Crocker, 2015; McLean et al., 2019; Sung et al., 2016), and their use might be defined as a "way of being" (Griffiths \& Kuss, 2017, p.1).

The "selfie" has been defined as self-taken photograph, typically taken with smartphones or webcams and shared on social media (Oxford Dictionary, 2013) and specific selfierelated activities as selfie-taking and -posting have been described as gendered processes (Albury, 2015) in which traditionally females showed higher engagement (Boursier \& Manna, 2018b; Boursier et al., 2020c; Chae, 2017; Dhir et al., 2016; Nguyen, 2014; Qiu et al., 2015; Sorokowska 
et al., 2016). However, both males and females seemed to utilize selfies for self-presentation purposes (Dutta et al., 2016; Guo et al., 2018; Katz \& Crocker, 2015) and the inclusion of both boys and girls, has been defined crucial (McLean et al., 2019). Overall, the taking and sharing photos by individuals may appear to be straightforward and innocuous activities, selfie behavior represents a nuanced, complex, and multidimensional phenomenon reflecting selfies intentional creation, and comprises multiple actions including taking (such as preparation and posing), modifying (such as editing and filtering), and posting onto SNSs (McLean et al., 2019). This phenomenon requires further research (Boursier \& Manna, 2018b; Bruno et al., 2018; McLean et al., 2019) to more fully understand the possible risks and opportunities related to selfie behavior (e.g., Boursier et al., 2020a; Boursier et al., 2020c; Boursier \& Manna, 2018b; Diefenbach \& Christoforakos, 2017; McLean et al., 2019). Concerning the opportunities offered by selfie-taking and selfie-sharing, some studies have shown that these activities appear to (i) provide new material for creative works, allowing creators to manage emotions (Bruno et al., 2018; Diefenbach \& Christoforakos, 2017), (ii) improve individuals' self-esteem and mood due to "likes" and positive feedback received from others (Reich et al., 2018; Toma, 2013), (iii) enhance selfconfidence and self-attractiveness (Boursier \& Manna, 2018b; Grogan et al., 2018), and (iv) contribute to relationship construction (Chua \& Chang, 2016; Sorokowska et al., 2016; Taylor et al., 2017). Other studies have found that selfietaking and selfie-sharing represent habitual behaviors that help pass the time, facilitated by needs to belong, document, archive, retain special moments, and be creative (Bij de Vaate et al., 2018; Etgar \& Amichai-Hamburger, 2017; Sung et al., 2016). Additionally, empirical findings have highlighted the value of selfies as a medium for self and identity exploration, allowing self-study and self-observation among young individuals (Diefenbach \& Christoforakos, 2017; Rutledge, 2013). However, highly appearance-focused self-presentation, which appears to be a crucial element in selfie-presentation, may also afford risks, particularly in relation to young individuals' body image (Boursier \& Manna, 2018b; Boursier et al., 2020a, 2020c; Chae, 2017; Bij de Vaate et al., 2018; Diefenbach \& Christoforakos, 2017; Lowe-Calverley \& Grieve, 2018; Lyu, 2016; McLean et al., 2019; Yau \& Reich, 2019), including selfie-related problematic behaviors (Balakrishnan \& Griffiths, 2018; Griffiths \& Balakrishnan, 2018; Monacis et al., 2020).

Body image typically plays a pivotal role in adolescent development and wellbeing and, during adolescence, boys and girls are typically required to face with physical changes, "new" body mentalization, and identity construction processes (de Vries et al., 2016; Franchina \& Lo Coco, 2018; Markey, 2010; Rudd \& Lennon, 2000). In this regard, social media might represent ideal places for adolescents' identity construction and exploration processes (Kuss \& Griffiths, 2017; Pelosi et al., 2014), and selfies might represent a medium for self-exploration, promoting self-study, and selfobservation (Diefenbach \& Christoforakos, 2017; Rutledge, 2013). Nevertheless, the increasing centrality of photos and visual self-presentation on SNSs may enhance young people's appearance-related concerns and potentially problematic monitoring of their own body image and photos (Fox \& Vendemia, 2016; Perloff, 2014). In this regard, the selfobjectification theory (Fredrickson \& Roberts, 1997; McKinley \& Hyde, 1996), seems to offer a useful framework through which specific selfie behaviors and the risks imparted by those behaviors have been examined. Indeed, this perspective highlighted individuals' tendency to experience and consider the body as an object assuming an observer's point of view. Therefore, how the body appears represents something to control in order to meet socio-cultural internalized body ideals and avoid negative judgements. In this perspective, a positive association between levels of self-objectification and selfie activities has been previously stated, including selfieposting among adolescent girls (Meier \& Gray, 2014; Zheng et al., 2019), and selfie-editing among both early adult women (Bell et al., 2018; Veldhuis et al., 2020; Cohen et al., 2018), and young adult men (Fox \& Rooney, 2015). Furthermore, in prospective analyses among adolescent boys and girls, reciprocal relationships between selfie behaviors and selfobjectification have been observed whereby selfie-viewing and selfie-editing predicted increases in self-objectification and baseline levels of self-objectification were also found to predict increases in selfie viewing, editing, and posting (Boursier et al., 2020c; Wang et al., 2019). As Diefenbach and Christoforakos (2017) stated, the self-camera might act as a mirror, or form of monitoring reflective of self-objectification, leading to an over-controlled self-presentation on SNSs that begins when taking a photo. According to previous studies (Boursier \& Manna, 2019; Bij de Vaate et al., 2018; McLean et al., 2015; Pelosi et al., 2014), photo investment and control over body image in pictures represent adolescents' and emerging adults' attempt to manage concerns about their own self-portrait quality and how they portray themselves, following specific strategies in taking and choosing selfies before sharing online. It is likely that disembodied, asynchronous, and often, anonymous SNS environments allow individuals to present their best and ideal self on SNSs through photobased activities, including editing, leading to some individuals problematically overinvest in their online body image (Boursier \& Manna, 2018b; Casale \& Fioravanti, 2017; Cohen et al., 2018; Bij de Vaate et al., 2018; Fox \& Rooney, 2015; Fox \& Vendemia, 2016; Lonergan et al., 2019; McLean et al., 2015; Zhao et al., 2008). As Chen et al. (2019) noted, SNSs provide endless opportunities for individuals to share their own best self (often digitally modified and edited) to others, which may alter their perception of 
beauty and authenticity (Diefenbach \& Christoforakos, 2017; Rajanala et al., 2018).

Previous studies have defined photo manipulation as the alteration and enhancement of selfies and photos through editing programs, computer software, or smartphone apps, before sharing on social media (Chae, 2017; McLean et al., 2015). Similar to photo investment, selfie-editing also appears to be related to individuals' virtual makeovers, fulfilling their desire to create an ideal online self-presentation (Chae, 2017; Lowe-Calverley \& Grieve, 2018). In this regard, females have been found active in manipulating photos and using photographic filters, more than male peers (Chae, 2017; Dhir et al., 2016; McLean et al., 2015, 2019; Mingoia et al., 2019). Differently, according to Mascheroni et al. (2015), both male and female adolescents reported commonly editing their pictures (such as smoothing out skin, making body parts smaller or bigger, adding interactive filters), in order to convey an ideal appearance, gain an ideal form of online self-presentation, and receive positive feedback (such as 'likes' or comments) (Boursier \& Manna, 2018b; Chae, 2017; Chua \& Chang, 2016; Nelson, 2013; Rajanala et al., 2018). In this regard, according to McLean et al. (2019), digital manipulation of photos and their posting on social media might generate social comparison with an ideal, but unrealistic, own and peers' online self-presentation, especially among adolescents. However, as Bij de Vaate et al. (2018) noted, scholarly research tends to focus on selfie-posting behavior, whereas very few studies have explored selfie practices emphasizing photo investment, manipulation, and underlined motivations as possible predictors (Bij de Vaate et al., 2018; Chae, 2017; Dhir et al., 2016; McLean et al., 2015, 2019). Indeed, personal expectancies (in particular positive outcome expectancies) have been identified as pivotal influence factors in individuals' decisions and behaviors (Dermen \& Cooper, 1994; Patrick \& Maggs, 2009; Reich et al., 2010), and likely expectancies would have a role in influencing decisions and behaviors related to the multidimensional nature of taking, modifying, and posting selfies. However, to date, few studies have explored motives and expectancies underlying selfie practice during adolescence (i.e., Boursier \& Manna, 2018b; Bij de Vaate et al., 2018). An exception is the study by Boursier and Manna (2018b) who developed a measure to facilitate exploration of adolescents' motives and expectancies underlying selfie practice. They identified three kinds of selfierelated expectancies: positive (i.e., self-presentation, self-promotion, self-confidence, and self-attractiveness), negative (i.e., lack of control of own photos, privacy concerns, web exposure, and the possible effects on significant relationships), and neutral expectancies (i.e., selfie-making as a daily activity). Although few studies have examined motives among adolescents, some research has explored motives underlying selfie practices in other populations. This research has recognized entertainment, communication, and special moment retention as the main motivations for selfie-posting among emerging and young adults and among parents (Boursier et al., 2020c; Bij de Vaate et al., 2018; Sung et al., 2016). Nevertheless, further research is needed.

In summary, previous studies confirm that selfie practice is a widespread daily activity and the increased social media use for sharing personal photos make adolescent body image an extremely contemporary issue (Boursier \& Manna, 2019; Franchina \& Lo Coco, 2018; Pelosi et al., 2014). Moreover, gender-related differences in selfie practices have been found, showing a traditionally higher engagement in selfie-taking, selfie-posting, and selfie-editing by girls compared with boys. Overall, selfie behavior appears to be a complex phenomenon that comprises not only selfie-sharing on social media but also taking and editing personal photos following specific control and manipulation strategies. However, according to the aforementioned literature, few studies have explored expectations underlying selfie-taking and selfie-editing as predictive factors of these behaviors. Therefore, in light of the popularity of selfie-taking and posting, as well as a new appreciation of the ease with which selfies may be edited and manipulated, the present paper comprises two related studies. The first study reports the adaptation, validation, and psychometric evaluation of the Photo Manipulation Scale (McLean et al., 2015) among an Italian adolescent sample. The second study aimed at evaluating the main and indirect effects of expectancies underlying selfie practice and appearance management in photos on adolescents' photo manipulation while exploring the moderating role of gender in a mediation model. It has been hypothesized that selfie-related expectancies might positively cross-sectionally predict adolescents' body appearance control and selfie-management (such as selfie-editing) before sharing online. Moreover, it was expected that gender would affect the relationship between selfie expectancies and photo manipulation.

\section{Study 1}

The first study tested the psychometric properties of the Italian version of the 10-item Photo Manipulation Scale (PMS; McLean et al., 2015) among a large sample of Italian adolescent boys and girls. McLean et al. (2015) defined photo manipulation as the alteration of photo elements (easily available using editing programs or apps), prior to sharing online. According to Mascheroni et al. (2015) both boys and girls commonly report editing their own photos (for example, smoothing out skin, making body parts smaller or bigger, adding filters such as a crown of flowers or puppy ears), before sharing on social networking sites, to convey an ideal appearance and achieve an ideal form of online self-presentation, and to receive positive feedback (such as 'likes' and supportive comments) (Boursier \& Manna, 2018b; Chae, 
2017; Chua \& Chang, 2016; Nelson, 2013; Rajanala et al., 2018). Translation of the measure and subsequent investigation of its psychometric properties will facilitate further research on the antecedents and consequences of photo manipulation, such as appearance monitoring, body concerns and dissatisfaction, self-esteem, self-promotion, and social comparison (e.g., Ahadzadeh et al., 2017; Chae, 2017; Chen et al., 2019; Diefenbach \& Christoforakos, 2017; Lyu, 2016; McLean et al., 2019). Therefore, the aim of the first study was to evaluate the factor structure of a revised version of PMS (McLean et al., 2015) among a sample of Italian adolescents.

\section{Methods}

\section{Participants and Procedure}

A total of 1353 adolescents were recruited from six Italian high schools. The school principals and parents were informed of the nature of the research and the measures used in generating the data, and they gave their consent for their children to participate. General information about the aim of the study was also announced in class. Participation was voluntary, confidentiality was assured, and all participants were informed that they could withdraw from the study at any time. All students agreed to participate and completed the survey questionnaires in a classroom setting via their smartphones, while researchers and teachers supervised the survey completion. The study was approved by the research team's University Research Ethics Committees and was conducted in accordance with the ethical guidelines for psychological research by the Italian Psychological Association.

\section{Measures}

Participants' reported their gender and age. They were then asked to complete the Italian version of the Photo Manipulation Scale (McLean et al., 2015). The scale comprises 10 items rated on a five-point-Likert scale, from 1 (Never) to 5 (Always) and evaluates how often adolescents manipulate and edit photos of themselves prior to sharing on SNSs (for example, "How often do you make yourself look skinnier?", "How often do you adjust the light/darkness of the photo?"). Due to the increasing use of interactive filters among teenagers, in the present study, an extra item was added ("How often do you use interactive filters [e.g., puppy ears, crown of flowers, etc.]?"). Two independent researchers translated the original 10-item PMS and then, in order to minimize the risk of linguistic distortions, it was back-translated (adding the new item concerning the use of interactive filters) into English by a professional English-speaking translator (Van de Vijver \& Poortinga, 2004). The final Italian version of PMS did not show meaningful differences from the original
English version. In the present study, the 11-item revised PMS was used.

\section{Statistical Analysis}

The suitability of the data for factor analysis was tested with the Kayser-Meyer-Olkin (KMO) measure of sampling adequacy and Bartlett's test of sphericity. Later, the exploratory factor analysis (EFA) was conducted, and the factor structure based on EFA was confirmed through confirmatory factor analysis (CFA) with independent samples. The two samples were obtained on two different occasions of data collection. The first involved 653 adolescents (Sample 1) to perform an initial EFA on the original 11-item PMS. In the second, 700 participants (Sample 2) were recruited to conduct the CFA. Due to items' deviation from the normal distribution, in all structural equation modeling analysis, maximum likelihood estimation robust to non-normality (MLR) in Mplus 8 was used (Muthén \& Muthén, 2012). To evaluate the overall model fit, several indexes were used: the comparative fit index (CFI) and the Tucker-Lewis Fit Index (TLI), for which values higher than 0.90 are desired (Bentler, 1990); root mean square error approximation (RMSEA) for which values smaller than 0.08 are desired (Browne \& Cudeck, 1993); and the standardized root mean square residuals (SRMR) for which value below 0.08 is considered a good fit (Kline, 2015). To evaluate the internal consistency of the scale, both Cronbach's $\alpha$ and Spearman-Brown coefficients were computed.

\section{Results}

\section{Descriptive Statistics}

Sample $1(N=653)$ comprised 361 girls $(55.3 \%)$ and 292 boys $(44.7 \%)$ with a mean age of 16.4 years $(\mathrm{SD}=3.06$ years). Sample $2(N=700)$ comprised 351 girls $(50.1 \%)$ and 349 boys $(49.9 \%)$ with a mean age of 16.1 years $(\mathrm{SD}=$ 1.52 years).

\section{Exploratory Factor Analysis}

According to the KMO criterion, sampling adequacy was very good $(\mathrm{KMO}=0.87)$. Bartlett's test of sphericity showed that the correlation matrix was suitable for factor analysis $\left(\chi^{2}=2272.63, \mathrm{df}=55, p<0.001\right)$. In Sample 1 $(N=653)$, the EFA was performed with MLR estimator and goemin oblique rotation to evaluate the factor structure of the 11 items. The acceptability of the factor solution was based on goodness of fit index, the interpretability of the solution, and salient factor loadings (.30). Firstly, according to the mono-factorial structure of the original Selfie Manipulation Scale (McLean et al., 2015), one-factor solution has been tested. However, the obtained fit was 
inadequate. Similarly, the two-factor solution provided an inadequate fit. Thus, a three-factor solution has been tested, providing the first adequate fit to the data, $\operatorname{MLR} \chi^{2}(25)=$ 38.368, $p=.04$; CFI $=.99 ;$ TLI $=.98 ; \mathrm{RMSEA}=.03,90 \%$ confidence interval (C.I.) [.005-.046]; SRMR $=.02$ (Table 1). Factor loadings are presented in Table 2. For the further development of this scale, items were selected according to the following criteria. First, items that had factor loadings lower than 0.30 were excluded. Second, items with salient cross-loadings of greater than 0.30 on two or more factors were excluded from further analyses. The three excluded items are in highlighted in italics in Table 2. As a result of the aforementioned criteria, Items 1,3 , and 8 of the original 11 items were subsequently removed from the final revised PMS.

\section{Confirmatory Factor Analysis}

Based on the previous EFA, a three-factor solution was tested with CFA on Sample $2(N=700)$. This model provided a good fit to the data $\left(\operatorname{MLR}^{2}[17]=72.771\right.$, $p<.001 ; \mathrm{CFI}=.95 ; \mathrm{TLI}=.91 ; \mathrm{RMSEA}=.068,90 \%$ C.I. [.053-.085]; SRMR = .045) (Fig. 1). The first factor comprised three items concerning the use of filters to modify or adjust the overall look of the photo (e.g., colors, brightness, contrast, etc.). This first factor was named photo filter use. The second factor comprised three items concerning body image modification. These items referred to making specific parts of the body look larger or smaller and making body shape skinnier or larger. This second factor was named body image manipulation. The third factor was named facial image manipulation and comprised two items concerning digitally correcting skin imperfections improving facial image. A second-order CFA has been tested where a second-order dimension labeled photo manipulation loaded on the three first-order dimensions. This model showed a very good fit, $\operatorname{MLR} \chi^{2}[17]=$ 72.770, $\mathrm{CFI}=.95 ; \mathrm{TLI}=.91 ; \mathrm{RMSEA}=.068,90 \%$ C.I. [.053-.085]; SRMR =.045). Loadings of the secondorder dimension on the first-order dimensions ranged between .60 and 1.02. The revised eight-item PMS showed good Cronbach's $\alpha$ value (.80), lower but comparable to the Cronbach's $\alpha$ value (.85) in the original study of McLean et al. (2015). The Cronbach's $\alpha$ values for PMS subscales were .67 (photo filter use), .75 (body image manipulation) .74 (facial image manipulation). Moreover, due to the changed length of the scale, the Spearman-Brown coefficients for the PMS and the twoitem facial image manipulation subscale were tested, showing a good reliability (.78 and .75 , respectively). Means, standard deviations, and bivariate correlations among factors of the eight-item PMS are shown in Table 3 .

\section{Brief Discussion}

The three-factor model of the eight-item PMS provided a good fit to the data (Table 1) and all items loaded significantly on their respective latent factors (Fig. 1). The PMS showed a good internal consistency and a good reliability despite the shorter length of the scale compared to the original PMS (McLean et al., 2015). Furthermore, the factors of the 8-item PMS (photo filter use, body image modification, and facial image manipulation) significantly and positively correlated with one another. A second-order dimension loaded on the three first-order dimensions indicating that a global score of photo manipulation might be reliably computed and used. Finally, the eight-item PMS showed an optimal Cronbach's $\alpha$, indicating a good internal consistency reliability of the instrument.

\section{Study 2}

Despite the popularity of selfie-related activities on social media, especially among young people, scientific interest appears limited to selfie-posting, demonstrating a lack of attention to photo manipulation and its predictors (e.g., Bij de Vaate et al., 2018; Chae, 2017; Dhir et al., 2016; McLean et al., 2015, 2019). Bij de Vaate et al. (2018) showed that prior to sharing self-portrays online, specific steps can occur. First, individuals might have specific motives (such as peer pressures, entertainment, habitual passing of time, and social interactions) and preoccupations (such as looking at, tagging, sharing, and commenting friends' visual content) concerning selfietaking. Second, after taking several photos, selfie-makers might strategically select the perceived best photo they would like to share on social media. Thirdly, individuals might apply filters and/or manipulate the photos and,
Table 1 Fit indices of the 1-3 factor solutions of the exploratory factor analysis

\begin{tabular}{llllllll}
\hline Model & MLRx $^{2}(\mathrm{df})$ & $p$ & CFI & TLI & RMSEA & 90\% CI & SRMR \\
\hline One-factor model & $287.984(44)$ & $<.001$ & .82 & .77 & .092 & $.082-.102$ & .068 \\
Two-factor model & $123.963(34)$ & $<.001$ & .93 & .89 & .064 & $.052-.076$ & .033 \\
Three-factor model & $38.368(25)$ & .04 & .99 & .98 & .029 & $.005-.046$ & .020 \\
\hline
\end{tabular}


Table 2 Exploratory factor analyses of the generated items

\begin{tabular}{|c|c|c|c|}
\hline & Factor 1 & Factor 2 & Factor 3 \\
\hline $\begin{array}{l}\text { 4. How often do you use a filter to change the overall look of the photo } \\
\text { (e.g., making it black and white, or blurring and smoothing images)? }\end{array}$ & $.913 * * *$ & .025 & -.013 \\
\hline \multicolumn{4}{|l|}{$\begin{array}{l}\text { [Quanto spesso usi un filtro per cambiare l'aspetto complessivo della foto } \\
\text { (per esempio, rendendola in bianco e nero o sfocandola e sfumando le } \\
\text { immagini)?] }\end{array}$} \\
\hline 6. How often do you adjust the light/darkness of the photo? & $.484 * * *$ & -.028 & .281 \\
\hline [Quanto spesso modifichi la luce/ombra delle foto?] & & & \\
\hline $\begin{array}{l}\text { 11. How often do you use interactive filters (e.g., dog's snout, flower crown, } \\
\text { etc.)? }\end{array}$ & $.330 * * *$ & .165 & .129 \\
\hline \multicolumn{4}{|l|}{$\begin{array}{l}\text { [Quanto spesso usi filtri interattivi/effetti (per esempio, orecchie, naso e } \\
\text { bocca da cagnolino, corona di fiori, ecc.)?] }\end{array}$} \\
\hline $\begin{array}{l}\text { 9. How often do you make specific part of your body look larger or look } \\
\text { smaller? }\end{array}$ & .011 & $.835 * * *$ & -.014 \\
\hline [Quanto spesso rendi specifiche parti del tuo corpo più grosse o più piccole?] & & & \\
\hline 5. How often do you make yourself look skinnier? & .042 & $.752 * * *$ & -.001 \\
\hline [Quanto spesso ti rendi più magro/a?] & & & \\
\hline 2. How often do you make yourself look larger? & -.069 & $.480 * * *$ & .035 \\
\hline [Quanto spesso ti rendi più grosso/a?] & & & \\
\hline 7. How often do you edit to hide blemishes like pimples? & .124 & .002 & $.749 * * *$ \\
\hline $\begin{array}{l}\text { [Quanto spesso modifichi le foto per nascondere difetti come i brufoli?] } \\
\text { 10. How often do you edit or use apps to smooth skin? }\end{array}$ & .005 & .156 & $.662 * * *$ \\
\hline $\begin{array}{l}\text { [Quanto spesso modifichi o usi applicazioni per rendere la pelle omogenea?] } \\
\text { 8. How often do you whiten your teeth? }\end{array}$ & -.034 & .371 & $.458 * * *$ \\
\hline [Quanto spesso rendi i tuoi denti più bianchi?] & & & \\
\hline $\begin{array}{l}\text { 3. How often do you highlight facial features (e.g., cheekbones ore eye } \\
\text { color/brightness)? }\end{array}$ & .197 & .292 & $.305 * * *$ \\
\hline $\begin{array}{l}\text { [Quanto spesso evidenzi caratteristiche del volto (per esempio, gli zigomi o il } \\
\text { colore degli occhi/luminosità)?] }\end{array}$ & & & \\
\hline 1. How often do you get rid of red eye? & .078 & .120 & $.218^{*}$ \\
\hline [Quanto spesso elimini gli occhi rossi?] & & & \\
\hline
\end{tabular}

Excluded items $(8,3,1)$ are in italic. Factor loadings $>.30$ are in bold. $* p<.05 ; * * * p<.001$ finally, they will post the selfie(s). The second and third steps may be undertaken to achieve specific motives and in response to particular preoccupations. Moreover, other studies have examined gender-related differences in selfie investment and manipulation, showing that female adolescents are more active in selfie-taking and selfie-posting, and manipulating photos and using photographic filters more than male adolescent SNS users (Dhir et al., 2016; McLean et al., 2019). However, despite previous studies

Table 3 Means, standard deviations, and bivariate correlations among factors of the eight-item Photo Manipulation Scale

\begin{tabular}{lllll}
\hline & Means (SD) & 1 & 2 & 3 \\
\hline Photo filters use & $2.69(1.03)$ & - & & \\
Body image manipulation & $1.31(.69)$ & $.431^{* * *}$ & - \\
Facial image manipulation & $1.70(1.03)$ & $.619^{* * *}$ & $.731 * * *$ & - \\
\hline
\end{tabular}

$* * * p<.001$ suggesting that motivations and expectancies play a pivotal role in determining young people's general behaviors and specific selfie-related activities (Boursier et al., 2020c; Dermen \& Cooper, 1994; Patrick \& Maggs, 2009; Reich et al., 2010), no previous studies have evaluated the possible predictive role of boys' and girls' selfie-expectancies (Boursier \& Manna, 2018b) concerning body image control and manipulation in photos, prior to sharing them online. Therefore, the second study tested a moderated mediation model, and evaluated the main and indirect effects of teens' selfieexpectancies and selfie appearance management on photo manipulation and the moderating role of gender in this mediation model. It was expected that selfieexpectancies would be positively associated with photo manipulation and that this relationship would be mediated by selfie appearance management such that higher selfie expectancies would be associated with greater selfie appearance management, which would, in turn, be associated with greater frequency of manipulation of photos. In 


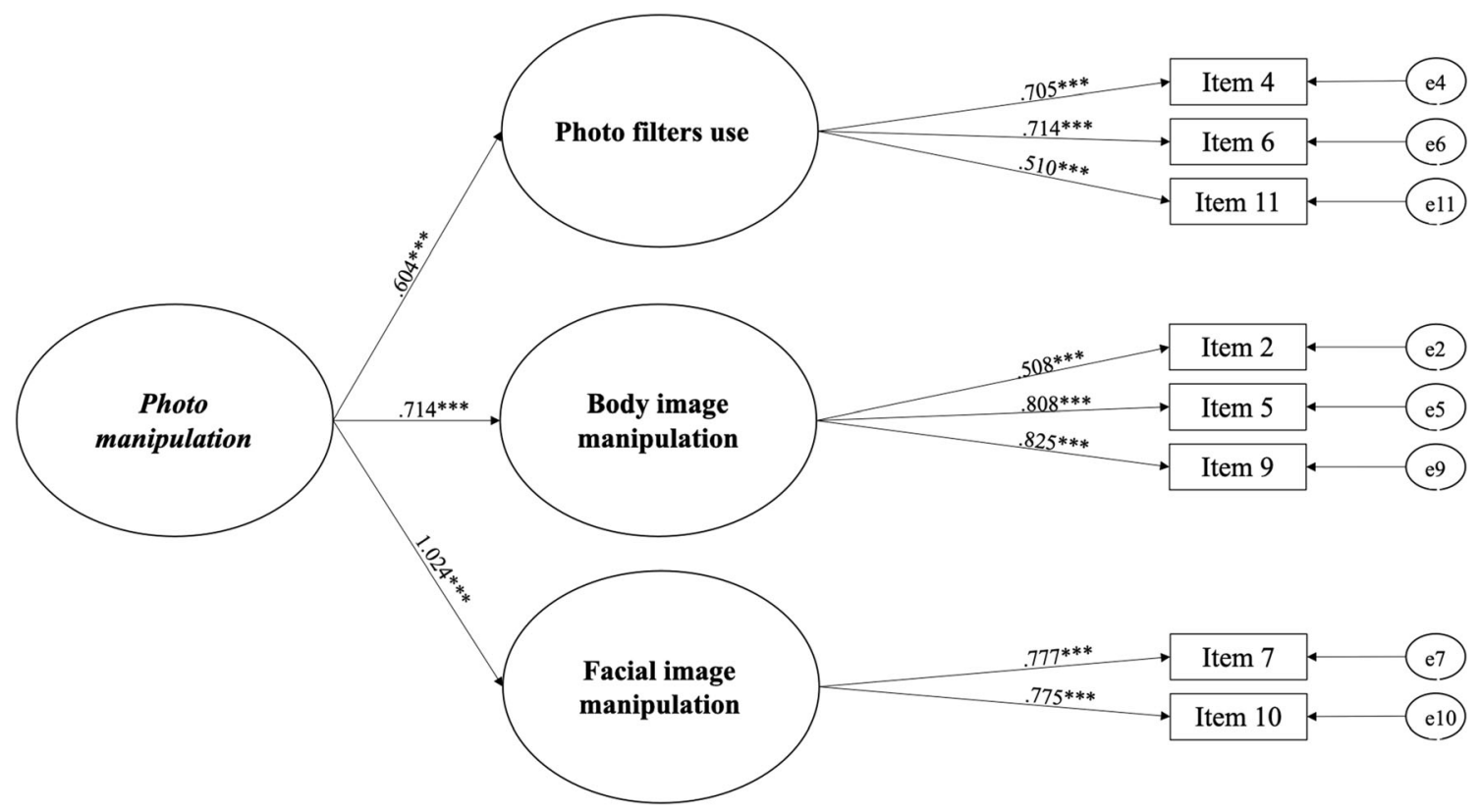

Fig. 1 First order three-factors model and second order factor tested with confirmatory factor analysis. Note. Errors associated three latent variables are not showed in order to improve figure readability. $* * * p<.001$

relation to gender moderation, it was expected that female gender would moderate the relationship between selfie expectancies and photo manipulation. This mediation and moderation models are presented in Figs. 2 and 3.

\section{Methods}

\section{Participants and Procedure}

A total of 453 adolescents from four different Italian high schools $(47 \%$ males; mean age $=16.1$ years, $\mathrm{SD}=1.46)$ participated in a survey study. General information about the aim of the study, nature of the research, and the measures to be used in generating the data were provided to school principals, parents, and students who gave their consent. Adolescents' participation was voluntary, confidentiality was assured, and all participants were informed that they could withdraw from the study at any time. All students agreed to participate and completed the survey questionnaires in a classroom setting via their smartphones, supervised by teachers and researchers. No course credits or remunerative rewards were given for participation. The study was approved by the research team's University Research Ethics Committees and was conducted in accordance with the ethical guidelines for psychological research by the Italian Psychological Association.

\section{Measures}

Selfie-Expectancies Scale (SES) The SES (Boursier \& Manna, $2018 \mathrm{~b}$ ) evaluates positive and negative expectancies concerning selfie-behavior. The scale comprises 23 items corresponding to seven different factors: relational worries (e.g., "How much selfie-taking might damage your reputation?"), web-related anxieties (e.g., "How much selfie-taking might worry you because your photos/identity could be stolen?"), sexual desire (e.g., "How much selfie-taking improves your sexual fantasies?"), ordinary practice (e.g., "How much selfie-taking is a habit?"), self-confidence (e.g., "How much selfie-taking improves your self-esteem?"), self-presentation (e.g., "How much selfie-taking is a way to show to the others the best part of you?"), and generalized risks (e.g., "How much selfie-taking might cause you problems in the future?"). Each item is answered on a five-point Likert scale ranging from 1 (totally disagree) to 5 (totally agree). In the present study, the Cronbach's $\alpha$ values for each SES subscale ranged from .65 to .87 , comparable with the values (ranged from .60

Fig. 2 The proposed mediation model

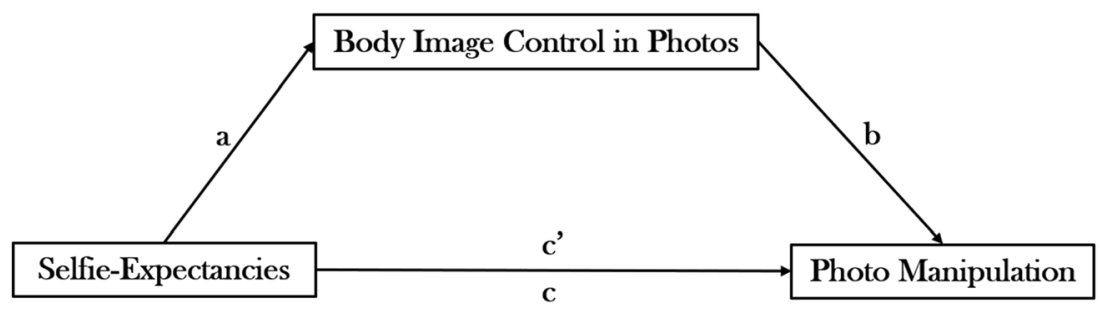


Fig. 3 Conceptual model of the moderated mediation relationship. Note: Gender should moderate the relationship between adolescents' selfieexpectancies and photo manipulation

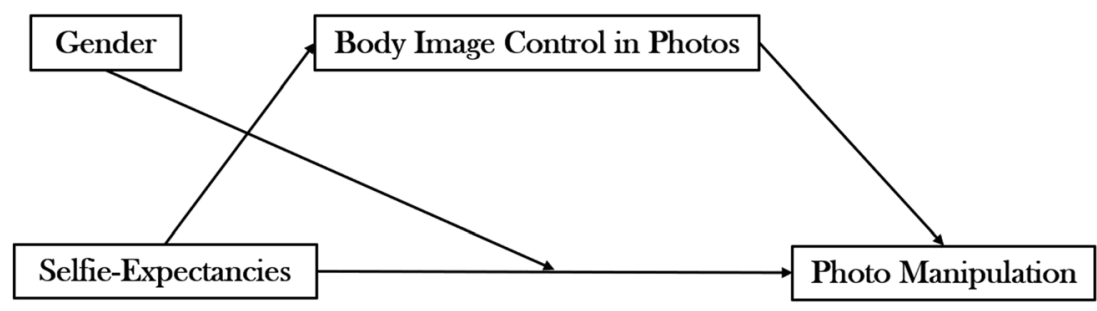

and .86) reported in the original study (Boursier \& Manna, 2018b).

Body Image Control in Photos-Revised (BICP-R) The original Body Image Control in Photos scale (Pelosi et al., 2014) was a 27-item scale, rated on a five-point-Likert scale from 1 (Never) to 5 (Always) and assesses adolescents' photo management and control online and offline. Boursier and Manna (2019) revised and reduced the length of the original instrument. The short version comprises 16 items corresponding to five different factors: selfie-related factors (e.g., "I prefer my image as it appears in self-portraits, because I know how to make it look better"), privacy filter behaviors (e.g. "I use privacy filters in order to show photos in which I appear more attractive only to certain people"), positive body image factors (e.g., "I post those photos which I hope will receive praise for my appearance"), sexual attraction factors (e.g., "I have posted provocative photos on Facebook, in order to attract attention to myself"), and negative body image factors (e.g., "Ifeel awkward if Inotice that someone has posted photos that show my body's defects"). In order to improve the interpretability, the name of BICP-R factors was modified compared to the previous version of the scale (Boursier \& Manna, 2019). In the present study, the Cronbach's $\alpha$ value for the scale was good (.81) and Cronbach's $\alpha$ values for each BICP-R subscale ranged from .62 to .76 , like the values (ranged from .65 and .77) of Boursier and Manna's (2019) study. There, Boursier and Manna (2019) also established a cut-off score for identifying individuals who problematically control their body image in photos and identified four categories: occasional (scores of 0-24), habitual (scores of 25-50), at-risk (scores of 51-55), and problematic (scores higher than 55).

Photo Manipulation Scale-Revised (PMS-R) The PMS, revised to an eight-item scale and validated in study 1 (original English version, McLean et al., 2015), was used in this second study to assess the frequency of photo manipulation. The global score of photo manipulation has been computed and used. According to the internal consistency values showed in Study 1 (.80) and in the original study of McLean et al. (2015) (.85), the Cronbach's $\alpha$ value for the PMS-R was good (.79).

\section{Statistical Analysis}

All statistical analyses were performed using the Statistical Package for Social Sciences SPSS (Version 23 for Windows). Firstly, skewness and kurtosis were calculated revealing that normality was met for all the study variables. Secondly, means, standard deviations of the variables, and confidence interval of means (CI: 95\%) estimated with 1000 bootstrap samples were assessed. Independent $t$-tests were used to detect gender differences. The effect sizes of the differences were evaluated with Cohen's $d$. Furthermore, bivariate Pearson's correlations have been tested to evaluate the strength of association between among variables. Later, a mediation analysis was conducted by using Model 4 of Hayes's (2017) Process Macro for SPSS with 1000 bias-corrected bootstrap samples to test the mediating effect of body image control in photos between adolescents' selfie expectancies and photo manipulation. Finally, a moderated mediation model was examined using the Process Macro (Hayes, 2017), applying Model 5 with 1000 bias-corrected bootstrap samples. In this model, the moderating role of gender on the mediation model was tested, specifically on the direct relationship between adolescents' selfie-expectancies and photo manipulation. According to Preacher et al. (2007), a moderating effect is demonstrated by the significant interaction of the independent variable and the moderator variable with the bootstrapped confidence intervals not containing zero.

\section{Results}

\section{Descriptive Statistics, Inferential Statistics, and Bivariate Correlations}

Descriptive analyses and gender differences are reported in Table 4. Statistically significant differences between boys' and girls' scores were found. Girls reported higher mean scores than boys for SES web-related anxieties, BICP privacy filter behaviors, BICP positive body image factors, BICP negative body image factors, BICP total score, and PM photo filters use. Effect sizes were small. In contrast, boys showed higher mean scores than girls for SES relational worries, SES sexual desire, SES generalized risks, SES total score, and PMS body image manipulation. Effect sizes were small to moderate. In terms of BICP descriptive cut-off categories, 
Table 4 Means, standard deviations (SDs), confidence intervals (CIs) estimated with 1000 bootstrap samples, $t$-test, and effects sizes (Cohen's d) for both genders

\begin{tabular}{|c|c|c|c|c|c|}
\hline & $\begin{array}{l}\text { Total sample } \\
\text { Mean (SD) } \\
{[95 \% \mathrm{CI}]}\end{array}$ & $\begin{array}{l}\text { Males } \\
\text { Mean (SD) } \\
{[95 \% \mathrm{CI}]}\end{array}$ & $\begin{array}{l}\text { Females } \\
\text { Mean (SD) } \\
{[95 \% \mathrm{CI}]}\end{array}$ & $t$ & $d$ \\
\hline SES relational worries & $\begin{array}{l}1.939(.947) \\
{[1.852-2.035]}\end{array}$ & $\begin{array}{l}2.039(.99) \\
{[1.9-2.176]}\end{array}$ & $\begin{array}{l}1.851(.901) \\
{[1.736-1.975]}\end{array}$ & $-2.119^{*}$ & .20 \\
\hline SES web-related anxieties & $\begin{array}{l}2.54(1.361) \\
{[2.405-2.662]}\end{array}$ & $\begin{array}{l}2.354(1.302) \\
{[2.179-2.534]}\end{array}$ & $\begin{array}{l}2.704(1.394) \\
{[2.515-2.886]}\end{array}$ & $2.752 * *$ & .25 \\
\hline SES sexual desire & $\begin{array}{l}1.645(.857) \\
{[1.571-1.725]}\end{array}$ & $\begin{array}{l}1.939(.973) \\
{[1.814-2.075]}\end{array}$ & $\begin{array}{l}1.386(.638) \\
{[1.305-1.468]}\end{array}$ & $-7.230 * * *$ & .68 \\
\hline SES ordinary practice & $\begin{array}{l}3.291(1.113) \\
{[3.185-3.391]}\end{array}$ & $\begin{array}{l}3.338(1.114) \\
{[3.194-3.485]}\end{array}$ & $\begin{array}{l}3.250(1.112) \\
{[3.103-3.385]}\end{array}$ & $-.837^{\text {n.s. }}$ & .08 \\
\hline SES self-confidence & $\begin{array}{l}2.107(1.067) \\
{[2.006-2.208]}\end{array}$ & $\begin{array}{l}2.156(1.093) \\
{[2.02-2.301]}\end{array}$ & $\begin{array}{l}2.064(1.044) \\
{[1.927-2.194]}\end{array}$ & $-.909^{\text {n.s. }}$ & .09 \\
\hline SES self-presentation & $\begin{array}{l}2.428(1.074) \\
{[2.325-2.526]}\end{array}$ & $\begin{array}{l}2.516(1.136) \\
{[2.371-2.674]}\end{array}$ & $\begin{array}{l}2.351(1.011) \\
{[2.225-2.482]}\end{array}$ & $-1.629^{\text {n.s. }}$ & .15 \\
\hline SES generalized risks & $\begin{array}{l}2.326(.903) \\
{[2.24-2.414]}\end{array}$ & $\begin{array}{l}2.429(.987) \\
{[2.312-2.561]}\end{array}$ & $\begin{array}{l}2.235(.814) \\
{[2.131-2.343]}\end{array}$ & $-2.293 *$ & .22 \\
\hline SES TOTAL & $\begin{array}{l}2.325(.665) \\
{[2.265-2.389]}\end{array}$ & $\begin{array}{l}2.396(.724) \\
{[2.303-2.488]}\end{array}$ & $\begin{array}{l}2.263(.602) \\
{[2.187-2.338]}\end{array}$ & $-2.127 *$ & .20 \\
\hline BICP selfie-related factors & $\begin{array}{l}2.28(.901) \\
{[2.197-2.358]}\end{array}$ & $\begin{array}{l}2.208(.959) \\
{[2.074-2.336]}\end{array}$ & $\begin{array}{l}2.344(.843) \\
{[2.24-2.449]}\end{array}$ & $1.606^{\text {n.s. }}$ & .15 \\
\hline BICP privacy filter behaviors & $\begin{array}{l}2.52(1.124) \\
{[2.422-2.62]}\end{array}$ & $\begin{array}{l}2.293(1.165) \\
{[2.132-2.444]}\end{array}$ & $\begin{array}{l}2.72(1.049) \\
{[2.588-2.853]}\end{array}$ & $4.108 * * *$ & .39 \\
\hline BICP positive body image factors & $\begin{array}{l}2.941(.619) \\
{[2.881-2.996]}\end{array}$ & $\begin{array}{l}2.857(.64) \\
{[2.778-2.951]}\end{array}$ & $\begin{array}{l}3.015(.591) \\
{[2.94-3.086]}\end{array}$ & $2.716^{* *}$ & .26 \\
\hline BICP sexual attraction factors & $\begin{array}{l}2.124(1.134) \\
{[2.027-2.224]}\end{array}$ & $\begin{array}{l}2.028(1.132) \\
{[1.876-2.18]}\end{array}$ & $\begin{array}{l}2.208(1.132) \\
{[2.062-2.363]}\end{array}$ & $1.681^{\text {n.s. }}$ & .16 \\
\hline BICP negative body image factors & $\begin{array}{l}2.038(.88) \\
{[1.96-2.119]}\end{array}$ & $\begin{array}{l}1.95(.921) \\
{[1.825-2.073]}\end{array}$ & $\begin{array}{l}2.116(.837) \\
{[2.018-2.232]}\end{array}$ & $2.016^{*}$ & .19 \\
\hline BICP TOTAL & $\begin{array}{l}2.381(.71) \\
{[2.317-2.444]}\end{array}$ & $\begin{array}{l}2.267(.782) \\
{[2.16-2.369]}\end{array}$ & $\begin{array}{l}2.48(.626) \\
{[2.406-2.563]}\end{array}$ & $3.221 * *$ & .30 \\
\hline PM photo filters use & $\begin{array}{l}2.643(1.031) \\
{[2.55-2.732]}\end{array}$ & $\begin{array}{l}2.404(1.076) \\
{[2.255-2.541]}\end{array}$ & $\begin{array}{l}2.853(.942) \\
{[2.733-2.978]}\end{array}$ & $4.738 * * *$ & .45 \\
\hline PM body image manipulation & $1.343(.724)$ & $1.506(.912)$ & $1.199(.458)$ & $-4.607 * * *$ & .43 \\
\hline PM facial image manipulation & $\begin{array}{l}{[1.28-1.408]} \\
1.711(1.009)\end{array}$ & $\begin{array}{l}{[1.373-1.635]} \\
1.757(1.103)\end{array}$ & $\begin{array}{l}{[1.139-1.258]} \\
1.67(.92)\end{array}$ & $-.915^{\text {n.s. }}$ & .09 \\
\hline PM Total & $\begin{array}{l}{[1.624-1.799]} \\
1.899(.735)\end{array}$ & $\begin{array}{l}{[1.613-1.908]} \\
1.889(.878)\end{array}$ & $\begin{array}{l}{[1.553-1.788]} \\
1.908(.583)\end{array}$ & $.266^{\text {n.s. }}$ & .03 \\
\hline & {$[1.833-1.962]$} & {$[1.772-2.009]$} & [1.835-1.989] & & \\
\hline
\end{tabular}

$S E S$, Selfie Expectancies Scale; BICP, Body Image Control in Photos; PM, Photo Manipulation ${ }^{*} p<.05 ; * *<.01 ; * * * p<.001 ;{ }^{\text {n.s. }}$ non-significant
9.3\% of the sample occasionally controlled their own body image in photos, $77.5 \%$ habitually controlled it, $7.1 \%$ controlled it in a risky way, and $6.2 \%$ controlled it in a problematic way. More specifically, a higher percentage of girls had risky control over own body image in photos than boys (girls $7.5 \%$ vs. boys' $6.6 \% ; p<.01$ ), while a higher percentage of boys had higher problematic control over their bodily appearance in photos than girls (boys $7.5 \%$ vs. girls' $5 \% ; p<.01$ ).

Bivariate correlations between all variables are shown in Table 5. Significant positive correlations were observed between selfie expectancy, body image control in photos, and photo manipulation subscales and total variables. In addition, significant positive correlations were observed between subscales of each assessment measure. Positive correlations of large effect size were observed among boys between selfie expectancy variables self-confidence and self-presentation and body image control in photo variables selfie-related factors and privacy filters, and the photo manipulation factor, filter use. In addition, the self-confidence selfie expectancy variable was correlated at large effect size with the negative body image factor from the body control in photos scale and use of facial manipulation from the photo manipulation scale. 


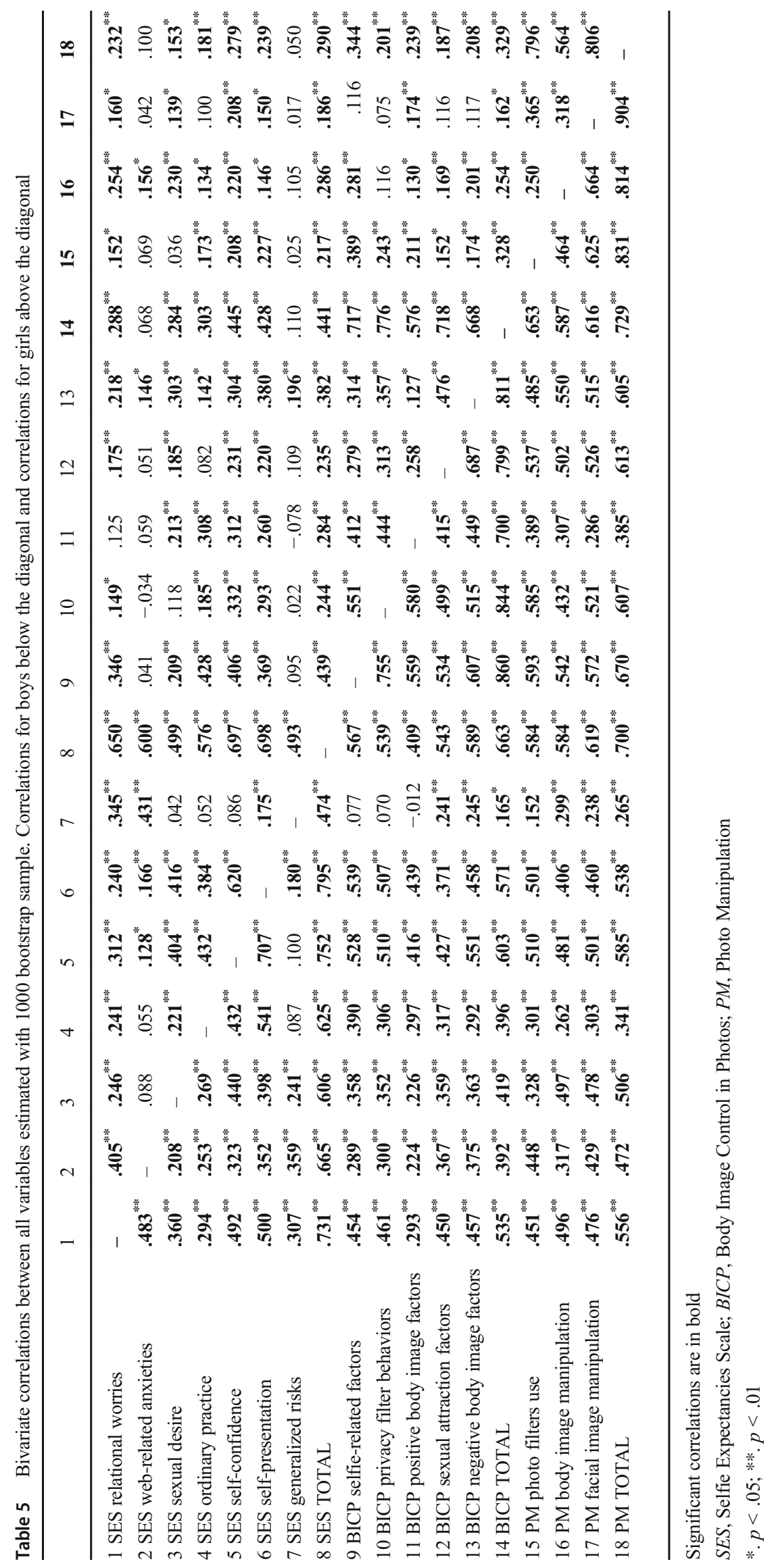


A similar pattern of significant associations was observed between these variables for girls. However, they did not reach a large effect size.

\section{Mediation Analysis}

The proposed mediation model (Fig. 2) was tested. As showed in Table 6, selfie-expectancies had a significant direct effect on body image control in photos $(\mathrm{a}: \beta=.580 ; \mathrm{SE}=.042 ; \mathrm{t}=$ $13.728 ; p<.001)$ and photo manipulation (c: $\beta=.353$; $\mathrm{SE}=.048 ; t=7.316 ; p<.001)$. Moreover, body image control in photos had a significant direct effect on photo manipulation (b: $\beta=.412 ; \mathrm{SE}=.045 ; t=9.126 ; p<.001$ ). Finally, the total effect of selfie-expectancies on photo manipulation was significant (c': $\beta=.591 ; \mathrm{SE}=.044 ; t=13.436 ; p<.001)$ and the bias-corrected bootstrapping mediation test indicated that selfie-expectancies predicted photo manipulation via body image control in photos $(\mathrm{a} * \mathrm{~b}: \beta=.239$; $\mathrm{SE}=.039$; Bootstrap $95 \%$ CI $[.166, .316] ; p<.001)$. The Sobel test showed that this model was significant $(Z=7.586 ; \mathrm{SE}=.032 ; p<.001)$ and it explained $39.7 \%$ of the total variance of photo manipulation.

\section{Moderated Mediation Analysis}

The moderated mediation test was conducted on the previously significant mediational model (Hayes, 2017) to examine whether gender moderated the mediation model, specifically the relationship between adolescents' selfie-expectancies and photo manipulation (Fig. 3). Gender added to the model (girls coded as 1 and boys coded as 2 ) negatively directly predicted photo manipulation $(\beta=-1.081 ; \mathrm{SE}=.195 ; t=-5.54$; $p<.001)$ and the interaction between selfie-expectancies and gender showed a significant moderating effect on the association between adolescents' selfie-expectancies and photo manipulation $(\beta=.471 ; \mathrm{SE}=.08 ; t=5.893 ; p<.001)$. The 1000 bias-corrected bootstrapped estimates showed a significant indirect effect of selfie-expectancies on photo manipulation via body image control in photos $(\beta=.219 ; \mathrm{SE}=.039$; Bootstrap $95 \%$ CI $[.15, .308])$ and for conditional direct effects of selfie-expectancies on photo manipulation bootstrapping estimates confirmed the significant gender effect on the relationship between the variables. More specifically, being female had no significant direct effect on the relationship between selfie-expectancies and photo manipulation $(\beta=.108 ; \mathrm{SE}=.063 ; t=1.715 ; p=.09 ;$ Bootstrap $95 \%$ CI $[-.016, .231])$, while being male had a significant and positive direct effect on the relationship between the variables $(\beta=.579 ; \mathrm{SE}=.062 ; t=9.380 ; p<.001 ;$ Bootstrap 95\% CI $[.458, .700])$. The simple slopes representing the relationship between gender and photo manipulation scores at $-1 \mathrm{SD}$, mean, and +1 SD values of selfie-expectancies are shown in Fig. 4. This shows that for girls, there was not a significant relationship between selfie expectancies and photo-manipulation, whereas, for boys, higher selfie expectancies were associated with greater levels of photo manipulation. The overall model was significant $\left(\mathrm{R}^{2}=.441 ; \mathrm{SE}=.305 ; \mathrm{F}_{(4,448)}=88.345\right.$; $p<.001)$.

\section{Brief Discussion}

In this second study, a moderated mediation model was crosssectionally tested in which body image control in photos mediated the association between expectancies underlying selfie behavior and photo manipulation, and gender moderated this relationship in a sample of Italian adolescents. Concerning the gender-related differences, selfie-expectancies, body image control in photos, and photo manipulation mean scores highlighted significant differences between male and female adolescents. Furthermore, the correlational study showed a significant and positive co-occurrence among variables, especially in male sample. The tested mediation model suggested that selfie-expectancies were both directly and indirectly (via body image control in photos) positively associated with photo manipulation among boys and girls. It is possible that greater expectations that taking selfies will bring particular outcomes might promote investment in photo-related activities and monitoring, consequently prompting the use of photo manipulation and editing strategies, especially among male adolescents. Indeed, surprisingly, the moderated mediation model showed that being female had no significant direct effect on the relationship between selfie-expectancies and photo
Table 6 Models of the effect of adolescents' selfie-expectancies on photo manipulation with mediating effect of body image control in photos

\begin{tabular}{|c|c|c|c|c|c|c|c|}
\hline & & \multicolumn{2}{|c|}{ Photo manipulation } & \multicolumn{2}{|c|}{ Body image control in photos } & \multicolumn{2}{|c|}{ Photo manipulation } \\
\hline & & $\beta$ & $t$ & $\beta$ & $t$ & $\beta$ & $t$ \\
\hline \multicolumn{2}{|c|}{ Selfie-expectancies } & .353 & $7.316^{* * * *}$ & .580 & $13.728 * * *$ & .591 & $13,436 * * *$ \\
\hline \multicolumn{2}{|c|}{ Body image control in photos } & & & & & .412 & $9.126 * * *$ \\
\hline $\mathrm{R}^{2}$ & $.397 * * *$ & & & & & & \\
\hline$F_{(2,450)}$ & 148.366 & & & & & & \\
\hline
\end{tabular}


Fig. 4 Simple slopes of selfieexpectancies scores and photo manipulation. Note: Straight lines indicate significant effects of the predictor on photo manipulation scores

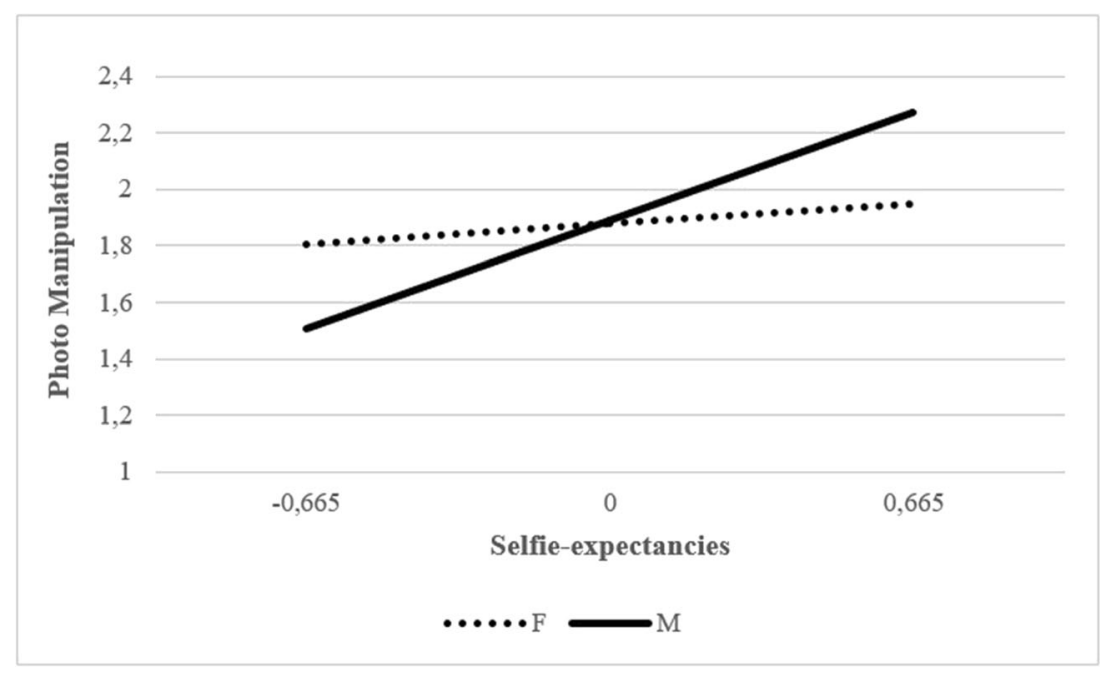

manipulation. On the contrary, being male had a significant and positive direct effect on the relationship between the variables, such that for boys, but not girls, higher selfie expectancies were associated with greater levels of photo manipulation. For girls, the level of photo manipulation was relatively consistent across different levels of selfie expectancies.

\section{General Discussion and Conclusions}

The present studies contribute to the understudied research field concerning factors associated with photo investment and manipulation. The psychometric properties of a photo manipulation instrument and a moderated mediation model were tested among a specific sample of 13 to 19-years old Italian boys and girls. In the first study, factor structure, validity, and reliability of a revised version of Photo Manipulation Scale (PMS) (McLean et al., 2015) were evaluated. The original version of the English scale was modified by adding an item concerning the use of interactive filters (such as a crown of flowers and puppy ears), widely used among teenagers (Rajanala et al., 2018). Following EFA and removal of three items from the original scale, CFA suggested that a threefactor solution provided the best fit to the data. The three emerging first order-factors were named: (i) photo filter use (usage of filters that modify or adjust the overall look of the photo); (ii) body image manipulation (editing specific parts of the body look larger or smaller, skinnier or larger); and (iii) facial image manipulation (digitally smoothing out skin imperfections to improve facial appearance). The resulting eightitem revised PMS showed good internal consistency and reliability, confirming the revised PMS to be a reliable instrument to evaluate photo manipulation strategies among Italian adolescents.

In the second study, gender differences between selfie expectancies, body image control in photos, and photo manipulation were tested, and correlations between variables were examined. In addition, selfie expectancies and body image control in photos were examined as direct and indirect cross-sectional predictors of photo manipulation using the revised PMS and tested in a moderated mediation model. Gender-related differences in mean scores for selfieexpectancies were found. Consistent with previous research (Boursier \& Manna, 2018b; Boursier et al., 2020c), relative to boys, girls appeared more worried about the risk that unknown individuals could steal or retouch their selfies, and about 'losing control' over their personal visual content, whereas boys (more than girls) expected that selfie practices might increase excitement and sexual fantasies and feelings. Interestingly, and in contrast to Boursier and Manna (2018b), in which the relational worries selfie expectancies factor did not show a significant gender difference and generalized risks factor mean score was higher among girls, in the present study both mean scores were higher among boys compared to girls. Therefore, despite (or due to) the crucial role of sexuality in males' selfie-related experiences, they showed higher mean scores than girls in negative expectancies underlying selfie practice. With regard to body image control in photos, previous studies (Boursier et al., 2020b; Boursier \& Manna, 2019; Gioia et al., 2020) highlighted a main condition of risk among girls in self-portrayal control online and offline. In the present study, despite female participants being more engaged in managing positive and negative images to promote their best selfpresentation, boys reported greater problematic control over their appearance in photos than did girls. Finally, genderrelated differences were found in photo manipulation scores. Girls used photo filters to improve the overall look of the photos more frequently than boys, whereas boys, more than girls, manipulated their body image making specific parts of the body look larger, smaller, or skinnier. It is likely that boys' greater risky control on their appearance in photos is related to their higher manipulation of body image in photos prior to 
their sharing on SNS. In addition to these descriptive findings, the correlation analysis confirmed that body image control in photos and photo manipulation significantly and positively co-occurred, especially in boys.

The tested mediation model demonstrated that selfieexpectancies were both directly and indirectly (via body image control in photos) positively associated with photo manipulation. Previous studies have shown the influence of expectations on decisions and risky behaviors such as drinking alcohol, sexual activities, sexting, and problematic Internet use (Boursier \& Manna, 2018b; Brand et al., 2014; Dermen \& Cooper, 1994; Dir et al., 2013; Turel \& Serenko, 2012). Similarly, the expectancies underlying selfie practice appeared to predict the (over)investment in photo-related activities and monitoring, in order to share an ideal appearance when posting self-images on SNS, consistent with previous research (Bij de Vaate et al., 2018; Fox \& Rooney, 2015; Fox \& Vendemia, 2016; Lonergan et al., 2019; McLean et al., 2015). Furthermore, the control over body image in photos appeared as another significant predictor of teens' photo manipulation. As noted by Bij de Vaate et al. (2018), this suggests that being engaged in thoughtful strategies to take the best photo to share online goes hand-in-hand with photo manipulation. In fact, body image control in photos positively mediated the relationship between selfie-expectancies and photo-editing. It is possible that expectations underlying selfie practice promote a possible excessive interest and commitment to a self-presentation that portrays an ideal appearance, and together these factors lead to greater photo manipulation before sharing online.

Recently, McLean et al. (2019) expressed the need to include boys as well as girls in research concerning selfie behavior. Consequently, in the present study, the participation of both males and females allowed the exploration of the influence of gender upon selfie practices. Indeed, the role of gender as a moderator might help to better explain the predictive role of selfie expectancies in photo manipulation. Contrary to several previous findings that found a female predominance in selfie-related activities and photo-editing strategies (Bij de Vaate et al., 2018; Dhir et al., 2016; McLean et al., 2015; Mingoia et al., 2019; Terán et al., 2019), the present findings showed that being male had a significant and positive direct effect on the relationship between selfie-expectancies and photo manipulation while being female did not influence the association between these variables. It is likely that males' expectations concerning selfie-taking and selfie-sharing (mainly negative or related to the sexual component of the selfies) directly predicted their photo-editing strategies, especially to manipulate their own body image. Moreover, the predictive role of selfie-expectancies increased due to the mediating role of the control over body image in photos. A possible interpretation of the current findings could be that girls engage in a consistent level of photo manipulation regardless of their selfie expectancies and body image control in photo behaviors, whereas for boys, photo manipulation may occur only under circumstances where they are more highly concerned about the outcomes of their selfie behaviors, such as presenting an ideal appearance. Consistent with this explanation, boys are increasingly becoming concerned about and involved in body image-related activities (Gioia et al., 2020; Vandenbosch \& Eggermont, 2013) in online and disembodied environments that allow individuals to edit and often problematically overinvest in their online appearance (Boursier \& Manna, 2018b; Casale \& Fioravanti, 2017; Cohen et al., 2018; Bij de Vaate et al., 2018; Fox \& Rooney, 2015; Fox \& Vendemia, 2016; Lonergan et al., 2019; McLean et al., 2015; Zhao et al., 2008). It is likely that overinvestment and reiteration of photo manipulation and editing activities might lead to a problematic selfie-sharing on social media. Furthermore, concerning self-objectification, the relationship between this kind of experiences and social media use might be bidirectional. Indeed, as some recent studies highlighted (Boursier et al., 2020b, 2020c; Gioia et al., 2020; Veldhuis et al., 2020), social media use and specifically visual content sharing might lead especially young people to strengthen selfobjectification processes allowing them to manage personal images online (Bell et al., 2018; Fardouly et al., 2015, 2017; Veldhuis et al., 2020), and engaging in potentially problematic social media use and body image-related activities (selfie enganement). In this regard, especially during adolescence, boys and girls are engaged in "new" body mentalization and identity construction processes, and the sharing of the own body images on social media assumes greater and increasing relevance (Boursier \& Manna, 2019; Franchina \& Lo Coco, 2018; Pelosi et al., 2014). Overall, it is likely that the relationship between social media and body image might be mutually reinforcing. Young people who are particularly concerned about their own body image might be more engaged in social media activities that focus on appearance and, at the same time, social media use and corresponding activities might exacerbate individuals' body image concerns due to the constant peer-to-peer comparison (Chen et al., 2019; Perloff, 2014; Webb et al., 2017).

\section{Practice Implications}

Interestingly, the present findings have many practical implications. The widespread use of social media platforms makes the body image-related issues extremely contemporary. In this regard, these findings might enhance the psychologists' and clinicians' attention toward teenagers' digital self-images on social media (King, 2016), helping them to better counsel adolescents about the integration and mentalization of a changing body. In this regard, the association between online body image-related issues and self-objectification experiences 
deserves clinicians and health workers attention suggesting a focus on the outcomes and mechanisms that underlie selfie practices (Veldhuis et al., 2020), thus supporting the adolescents' identity construction processes and making them aware of the risk of digitally modified body standards internalization. Finally, the present findings might also help in planning and developing intervention and school-based programs, addressed not only to girls but also to boys who are increasingly becoming involved in and concerned about online appearance-related activities (Vandenbosch \& Eggermont, 2013). In this regard, media literacy programs might be useful tools to educate teenagers about own real body image, about culturally and peer-to-peer promoted body standards, and about their selfie-sharing on social media (Fardouly et al., 2015; McLean et al., 2016).

\section{Limitations and Future Directions}

The novel findings of the present study provide evidence of the constant evolution of the social media landscape, with many platforms being replaced by new ones which are increasingly focused on visual content, especially among adolescents (Gioia \& Boursier, 2019a; Feltman \& Szymanski, 2018). Therefore, further research concerning selfie behavior, consisting of selfie-taking with its strategies, selfie-editing and manipulation, and selfie-sharing, are needed. In addition, further research to examine the consequences of engaging in photo manipulation are needed to determine the extent to which this enhanced focus on appearance contributes to the emergence of other problems, such as body dissatisfaction.

Some limitations of the present studies need to be addressed when interpreting the findings. First, the studies used a self-report method, and its potential biases are well-known. Second, the samples came from a specific Italian geographic area and the results of both studies might not be representative of other contexts or cultures. Third, the cross-sectional nature of the study precludes the ability to formally evaluate the causality of the variables involved in the present study. Furthermore, although the sample was roughly gender-balanced, the first study did not explore the validity of the revised eight-item PMS across male and female groups. Finally, the present studies only explored a small number of variables in relation to the complex phenomenon of selfie-behavior. Other aspects should be explored alongside the variables investigated here. For example, photo manipulation and editing could be explored in association with self-objectification experiences, body image-related issues, and other online creative or problematic activities. Nevertheless, the present studies' findings provided some novel and previously unreported issues. They demonstrated the good psychometric properties of the revised PMS, providing an appropriate instrument to assess adolescents' photo manipulation strategies. Moreover, the findings showed a strong association between expectancies underlying selfie practice and more or less problematic strategies concerning body image monitoring and manipulation. More specifically, and unexpectedly, the present findings provided novel and unreported gender differences that highlight modifications concerning appearance-related issues and online activities carried out by both boys and girls.

Acknowledgements The authors thank the schools, teachers, and adolescents who participated in the research. The authors also thank Dr. Federica Coppola for her help in collecting data and Dr. Concetta Esposito for her help in mediation model analysis.

Funding Open access funding provided by Università degli Studi di Napoli Federico II within the CRUI-CARE Agreement.

Data Availability The datasets generated during and/or analyzed during the current study are available from the corresponding author on reasonable request.

\section{Declarations}

Conflict of Interest The authors declare that they have no conflict of interest.

Open Access This article is licensed under a Creative Commons Attribution 4.0 International License, which permits use, sharing, adaptation, distribution and reproduction in any medium or format, as long as you give appropriate credit to the original author(s) and the source, provide a link to the Creative Commons licence, and indicate if changes were made. The images or other third party material in this article are included in the article's Creative Commons licence, unless indicated otherwise in a credit line to the material. If material is not included in the article's Creative Commons licence and your intended use is not permitted by statutory regulation or exceeds the permitted use, you will need to obtain permission directly from the copyright holder. To view a copy of this licence, visit http://creativecommons.org/licenses/by/4.0/.

\section{References}

Ahadzadeh, A. S., Sharif, S. P., \& Ong, F. S. (2017). Self-schema and self-discrepancy mediate the influence of Instagram usage on body image satisfaction among youth. Computers in Human Behavior, 68, 8-16. https://doi.org/10.1016/j.chb.2016.11.011.

Albury, K. (2015). Selfies| selfies, sexts and sneaky hats: Young people's understandings of gendered practices of self-representation. International Journal of Communication, 9, $12 \mathrm{http}: / / \mathrm{hdl}$.handle. net/1959.3/438132.

Balakrishnan, J., \& Griffiths, M. D. (2018). An exploratory study of "selfitis" and the development of the Selfitis behavior scale. International Journal of Mental Health and Addiction, 16(3), 722736. https://doi.org/10.1007/s11469-017-9844-x.

Bell, B. T., Cassarly, J. A., \& Dunbar, L. (2018). Selfie-objectification: Self-objectification and positive feedback ("likes") are associated with frequency of posting sexually objectifying self-images on social media. Body Image, 26, 83-89. https://doi.org/10.1016/j. bodyim.2018.06.005. 
Bentler, P. M. (1990). Comparative fit indexes in structural models. Psychological Bulletin, 107(2), 238-246. https://doi.org/10.1037/ 0033-2909.107.2.238.

Bij de Vaate, A. J. N. B., Veldhuis, J., Alleva, J. M., Konijn, E. A., \& van Hugten, C. H. (2018). Show your best self(ie): An exploratory study on selfie-related motivations and behavior in emerging adulthood. Telematics and Informatics, 35(5), 1392-1407. https://doi.org/10. 1016/j.tele.2018.03.010

Boursier, V., Gioia, F., \& Griffiths, M. D. (2020a). Do selfie-expectancies and social appearance anxiety predict adolescents' problematic social media use? Computers in Human Behavior, 110, 106395. https://doi.org/10.1016/j.chb.2020.106395.

Boursier, V., Gioia, F., \& Griffiths, M. D. (2020b). Objectified body consciousness, body image control in photos, and problematic social networking: The role of appearance control beliefs. Frontiers in Psychology, 11(147), 1-11. https://doi.org/10.3389/fpsyg.2020. 00147.

Boursier, V., Gioia, F., \& Griffiths, M. D. (2020c). Selfie-engagement on social media: Pathological narcissism, positive expectation, and body objectification-which is more influential? Addictive Behaviors Reports. Advance online publication., 11, 100263. https://doi.org/10.1016/j.abrep.2020.100263.

Boursier, V., \& Manna, V. (2018a). Problematic linkages in adolescents: Italian adaptation of a measure for internet-related problems. In Psychological, social, and cultural aspects of internet addiction (pp. 253-282). IGI Global. https://doi.org/10.4018/978-1-52258900-6.ch015.

Boursier, V., \& Manna, V. (2018b). Selfie expectancies among adolescents. Construction and validation of an instrument to assess expectancies toward selfies among boys and girls. Frontiers in Psychology, 9, 839. https://doi.org/10.3389/fpsyg.2018.00839.

Boursier, V., \& Manna, V. (2019). Relational body identities: Body image control through self-portraits -a revision of the body image control in photos questionnaire. In Intimacy and developing personal relationships in the virtual world (pp. 40-63). IGI Global. https:// doi.org/10.4018/978-1-5225-4047-2.ch003.

Brand, M., Laier, C., \& Young, K. S. (2014). Internet addiction: Coping styles, expectancies, and treatment implications. Frontiers in Psychology, 5, 1256. https://doi.org/10.3389/fpsyg.2014.01256.

Browne, M. W., \& Cudeck, R. (1993). Alternative ways of assessing model fit. Sage Focus Editions, 154, 136-136.

Bruno, N., Pisanski, K., Sorokowska, A., \& Sorokowski, P. (2018). Understanding selfies. Frontiers in Psychology, 9, 44. https://doi. org/10.3389/fpsyg.2018.00044.

Bryant, P., \& Bryant, J. A. (2005). Adolescents and the internet. Adolescent Medicine Clinics, 16(2), 413-426. https://doi.org/10. 1016/j.admecli.2005.03.001.

Casale, S., \& Fioravanti, G. (2017). Shame experiences and problematic Social networking sites use: An unexplored association. Clinical Neuropsychiatry, 14(1), 44-48 https://flore.unifi.it/retrieve/handle/ 2158/1074075/212427/2017_shame_PIU_Clin_Neur.pdf.

Chae, J. (2017). Virtual makeover: Selfie-taking and social media use increase selfie-editing frequency through social comparison. Computers in Human Behavior, 66, 370-376. https://doi.org/10. 1016/j.chb.2016.10.007

Chen, J., Ishii, M., Bater, K. L., Darrach, H., Liao, D., Huynh, P. P., Reh, I. P., Nellis, J. C., Kumar, A. R., \& Ishii, L. E. (2019). Association between the use of social media and photograph editing applications, self-esteem, and cosmetic surgery acceptance. JAMA Facial Plastic Surgery, 21(5), 361-367. https://doi.org/10.1001/jamafacial. 2019.0328

Chua, T. H. H., \& Chang, L. (2016). Follow me and like my beautiful selfies: Singapore teenage girls' engagement in self-presentation and peer comparison on social media. Computers in Human Behavior, 55, 190-197. https://doi.org/10.1016/j.chb.2015.09.011.
Cohen, R., Newton-John, T., \& Slater, A. (2018). 'Selfie'-objectification: The role of selfies in self-objectification and disordered eating in young women. Computers in Human Behavior, 79, 68-74. https:// doi.org/10.1016/j.chb.2017.10.027.

D'Arienzo, M. C., Boursier, V., \& Griffiths, M. D. (2019). Addiction to social media and attachment styles: A systematic literature review. International Journal of Mental Health and Addiction, 17, 1094 1118. https://doi.org/10.1007/s11469-019-00082-5.

d'Aloia, A., \& Parisi, F. (2016). Snapshot culture: The photographic experience in the post-medium age. Comunicazioni Sociali, 1, 3-14 http://hdl.handle.net/11591/400308.

de Vries, D. A., Peter, J., de Graaf, H., \& Nikken, P. (2016). Adolescents' social network site use, peer appearance-related feedback, and body dissatisfaction: Testing a mediation model. Journal of Youth and Adolescence, 45(1), 211-224. https://doi.org/10.1007/s10964-0150266-4.

Dermen, K. H., \& Cooper, M. L. (1994). Sex-related alcohol expectancies among adolescents: I. Scale development. Psychology of Addictive Behaviors, 8(3), 152-160. https://doi.org/10.1037/0893-164X.8.3. 152.

Dhir, A., Pallesen, S., Torsheim, T., \& Andreassen, C. S. (2016). Do age and gender differences exist in selfie-related behaviours? Computers in Human Behavior, 63, 549-555. https://doi.org/10.1016/j.chb. 2016.05.053.

Diefenbach, S., \& Christoforakos, L. (2017). The selfie paradox: Nobody seems to like them yet everyone has reasons to take them. An exploration of psychological functions of selfies in self-presentation. Frontiers in Psychology, 8, 7. https://doi.org/10.3389/fpsyg.2017. 00007.

Dir, A. L., Coskunpinar, A., Steiner, J. L., \& Cyders, M. A. (2013). Understanding differences in sexting behaviors across gender, relationship status, and sexual identity, and the role of expectancies in sexting. Cyberpsychology, Behavior and Social Networking, 16(8), 568-574. https://doi.org/10.1089/cyber.2012.0545.

Dutta, E., Sharma, P., Dikshit, R., Shah, N., Sonavane, S., Bharati, A., \& Sousa, A. D. (2016). Attitudes toward selfie taking in school-going adolescents: An exploratory study. Indian Journal of Psychological Medicine, 38(3), 242-245. https://doi.org/10.4103/0253-7176. 183094.

Etgar, S., \& Amichai-Hamburger, Y. (2017). Not all selfies took alike: Distinct selfie motivations are related to different personality characteristics. Frontiers in Psychology, 8, 842. https://doi.org/10.3389/ fpsyg.2017.00842.

Fardouly, J., Diedrichs, P. C., Vartanian, L. R., \& Halliwell, E. (2015). Social comparisons on social media: The impact of Facebook on young women's body image concerns and mood. Body Image, 13, 38-45. https://doi.org/10.1016/j.bodyim.2014.12.002.

Fardouly, J., Pinkus, R. T., \& Vartanian, L. R. (2017). The impact of appearance comparisons made through social media, traditional media, and in person in women's everyday lives. Body Image, 20, $31-$ 39. https://doi.org/10.1016/j.bodyim.2016.11.002.

Feltman, C. E., \& Szymanski, D. M. (2018). Instagram use and selfobjectification: The roles of internalization, comparison, appearance commentary, and feminism. Sex Roles, 78(5-6), 311-324. https:// doi.org/10.1007/s11199-017-0796-1.

Fox, J., \& Rooney, M. C. (2015). The dark triad and trait selfobjectification as predictors of men's use and self-presentation behaviors on social networking sites. Personality and Individual Differences, 76, 161-165. https://doi.org/10.1016/j.paid.2014.12. 017.

Fox, J., \& Vendemia, M. A. (2016). Selective self-presentation and social comparison through photographs on social networking sites. Cyberpsychology, Behavior and Social Networking, 19(10), 593600. https://doi.org/10.1089/cyber.2016.0248.

Franchina, V., \& Lo Coco, G. (2018). The influence of social media use on body image concerns. International Journal of Psychoanalysis 
and Education, 10(1), 5-14. File:///C:/users/franc/downloads/218661-1-PB.Pdf.

Fredrickson, B. L., \& Roberts, T. A. (1997). Objectification theory: Toward understanding women's lived experiences and mental health risks. Psychology of Women Quarterly, 21(2), 173-206. https://doi. org/10.1111/j.1471-6402.1997.tb00108.x.

Gioia, F., \& Boursier, V. (2019a). Emotion dysregulation and adolescents' preference for online social interactions: The moderating role of gender. Advance online publication. http://ceur-ws.org/Vol2524/paper23.pdf

Gioia, F., \& Boursier, V. (2019b). Treatment of internet addiction and internet gaming disorder in adolescence: A systematic review. In Multifaceted Approach to Digital Addiction and Its Treatment (pp. 157-176). Hershey, PA; IGI Global. https://doi.org/10.4018/978-15225-8449-0.ch008.

Gioia, F., Griffiths, M. D., \& Boursier, V. (2020). Adolescents' body shame and social networking sites: The mediating effect of body image control in photos. Sex Roles, 83(11), 773-785. https://doi. org/10.1007/s11199-020-01142-0.

Griffiths, M. D., \& Balakrishnan, J. (2018). The psychosocial impact of excessive selfie-taking in youth: A brief overview. Education and Health, 36(1), 3-6 http://irep.ntu.ac.uk/id/eprint/33263.

Griffiths, M. D., \& Kuss, D. (2017). Adolescent social media addiction (revisited). Education and Health, 35(3), 49-52 http://irep.ntu.ac. uk/id/eprint/31776/1/PubSub9230_Griffiths.pdf.

Grogan, S., Rothery, L., Cole, J., \& Hall, M. (2018). Posting selfies and body image in young adult women: The selfie paradox. Journal of Social Media in Society, 7(1), 15-36 https://e-space.mmu.ac.uk/id/ eprint/618951.

Guo, M., Liu, R. D., Ding, Y., Hu, B., Zhen, R., Liu, Y., \& Jiang, R. (2018). How are extraversion, exhibitionism, and gender associated with posting selfies on WeChat friends' circle in Chinese teenagers? Personality and Individual Differences, 127, 114-116. https://doi. org/10.1016/j.paid.2018.01.042.

Hayes, A. F. (2017). Introduction to mediation, moderation, and conditional process analysis: A regression-based approach. Guilford Publications.

Katz, J. E., \& Crocker, E. T. (2015). Selfies| selfies and photo messaging as visual conversation: Reports from the United States, United Kingdom and China. International Journal of Communication, 9(12), 1861-1872 https://ijoc.org/index.php/ijoc/article/viewFile/ $3180 / 1405$.

King, V. (2016). "If you show your real face, you'll lose 10000 followers" - The gaze of the other and transformations of shame in digitalized relationships. CM Komunikacija i Mediji, 11(38), 71-90. https://doi.org/10.5937/comman12-11504

Kurcaburun, K., Kokkinos, C. M., Demetrovics, Z., Király, O., Griffiths, M. D., \& Çolak, T. S. (2019). Problematic online behaviors among adolescents and emerging adults: Associations between cyberbullying perpetration, problematic social media use, and psychosocial factors. International Journal of Mental Health and Addiction, 17(4), 891-908. https://doi.org/10.1007/s11469-0189894-8.

Kline, R. B. (2015). Principles and practice of structural equation modeling (2nd ed.). Guilford Press.

Kuss, D. J., \& Griffiths, M. D. (2017). Social networking sites and addiction: Ten lessons learned. International Journal of Environmental Research and Public Health, 14(3), 1-17. https:// doi.org/10.3390/ijerph14030311.

Lonergan, A. R., Bussey, K., Mond, J., Brown, O., Giffiths, S., Muray, S. B., \& Mitchison, D. (2019). Me, my selfie, and I: The relationship between editing and posting selfies and body dissatisfaction in men and women. Body Image, 28, 39-43. https://doi.org/10.1016/j. bodyim.2018.12.001.
Lowe-Calverley, E., \& Grieve, R. (2018). Self-ie love: Predictors of image editing intentions on Facebook. Telematics and Informatics, 35(1), 186-194. https://doi.org/10.1016/j.tele.2017.10.011.

Lyu, S. O. (2016). Travel selfies on social media as objectified self-presentation. Tourism Management, 54, 185-195. https://doi.org/10. 1016/j.tourman.2015.11.001.

Markey, C. N. (2010). Invited commentary: Why body image is important to adolescent development. Journal of Youth and Adolescence 39, 1387-1391. https://doi.org/10.1007/s10964-010-9510-0.

Mascheroni, G. \& Ólafsson, K. (2018). Accesso, usi, rischi e opportunità di internet per i ragazzi Italiani. I primi risultati di EU Kids Online 2017. EU Kids Online and OssCom. Retrieved April 9, 2020, from: http://www.1se.ac.uk/media-and-communications/assets/ documents/research/eu-kids-online/reports/EU-Kids-Online-Italyreport-06-2018.pdf

Mascheroni, G., Vincent, J., \& Jimenez, E. (2015). Girls are addicted to likes so they post semi-naked selfies": Peer mediation, normativity and the construction of identity online. Cyberpsychology: Journal of Psychosocial Research on Cyberspace, 9(1), 5, 1-15. http://eprints. lse.ac.uk/id/eprint/62933

McKinley, N. M., \& Hyde, J. S. (1996). The objectified body consciousness scale: Development and validation. Psychology of Women Quarterly, 20(2), 181-215. https://doi.org/10.1111/j.1471-6402. 1996.tb00467.x.

McLean, S. A., Jarman, H. K., \& Rodgers, R. F. (2019). How do "selfies" impact adolescents' well-being and body confidence? A narrative review. Psychology Research and Behavior Management, 12, 513-521 https://www.ncbi.nlm.nih.gov/pmc/articles/ PMC6628890/pdf/prbm-12-513.pdf.

McLean, S. A., Paxton, S. J., \& Wertheim, E. H. (2016). Does media literacy mitigate risk for reduced body satisfaction following exposure to thin-ideal media? Journal of Youth and Adolescence, 45(8), 1678-1695. https://doi.org/10.1007/s10964-016-0440-3.

McLean, S. A., Paxton, S. J., Wertheim, E. H., \& Masters, J. (2015). Photoshopping the selfie: Self photo editing and photo investment are associated with body dissatisfaction in adolescent girls. International Journal of Eating Disorders, 48(8), 1132-1140. https://doi.org/10.1002/eat.22449.

Meier, E. P., \& Gray, J. (2014). Facebook photo activity associated with body image disturbance in adolescent girls. Cyberpsychology, Behavior and Social Networking, 17(4), 199-206. https://doi.org/ 10.1089/cyber.2013.0305.

Mingoia, J., Hutchinson, A. D., Gleaves, D. H., \& Wilson, C. (2019). The relationship between posting and photo manipulation activities on social networking sites and internalization of a tanned ideal among Australian adolescents and young adults. Social Media + Society, 5(1), 1-10. https://doi.org/10.1177/2056305118820419.

Monacis, L., Griffiths, M. D., Limone, P., Sinatra, M., \& Servidio, R. (2020). Selfitis behavior: Assessing the Italian version of the selfitis behavior scale and its mediating role in the relationship of dark traits with social media addiction. International Journal of Environmental Research and Public Health, 17(16), 5738. https://doi.org/10.3390/ ijerph17165738.

Musetti, A., Corsano, P., Boursier, V., \& Schimmenti, A. (2020) Problematic internet use in lonely adolescents: The mediating role of detachment from parents. Clinical Neuropsychiatry, 17(1), 3-10 https://doi.org/10.36131/clinicalnpsych20200101.

Muthén, L. K., \& Muthén, B. O. (2012). MPlus: Statistical analysis with latent variables. User's guide. Muthén \& Muthén.

Nelson, O. (2013). Dark undercurrents of teenage girls' selfies. The Age. Retrieved May 12, 2020, from: http:/www.theage.com.au/ comment/dark-undercurrents-of-teenage-girls-selfies-201307102pqbl.html\#ixzz2h9I59rtY.

Nguyen, A. J. (2014). Exploring the selfie phenomenon: the idea of selfpreservation and its implications among young women. Masters 
Thesis, Smith College, Northampton, MA. https://scholarworks. smith.edu/theses/792

Oxford Dictionary (2013) Selfie. Available at https://www. oxfordlearnersdictionaries.com/definition/english/selfie

Patrick, M. E., \& Maggs, J. L. (2009). Does drinking lead to sex? Daily alcohol-sex behaviors and expectancies among college students. Psychology of Addictive Behaviors, 23(3), 472-481. https://doi. org/10.1037/a0016097.

Pelosi, A., Zorzi, G., \& Corsano, P. (2014). The body image control in photos questionnaire (BICP). BPA-Applied Psychology Bulletin (Bollettino di Psicologia Applicata), 62(269), 42-52.

Perloff, R. M. (2014). Social media effects on young women's body image concerns: Theoretical perspectives and an agenda for research. Sex Roles, 71(11-12), 363-377.

Preacher, K. J., Rucker, D. D., \& Hayes, A. F. (2007). Addressing moderated mediation hypotheses: Theory, methods, and prescriptions. Multivariate Behavioral Research, 42(1), 185-227. https://doi.org/ 10.1080/00273170701341316

Qiu, L., Lu, J., Yang, S., Qu, W., \& Zhu, T. (2015). What does your selfie say about you? Computers in Human Behavior, 52, 443-449. https://doi.org/10.1016/j.chb.2015.06.032.

Rajanala, S., Maymone, M. B., \& Vashi, N. A. (2018). Selfies-Living in the era of filtered photographs. JAMA Facial Plastic Surgery, 20(6), 443-444. https://doi.org/10.1001/jamafacial.2018.0486.

Reich, R. R., Below, M. C., \& Goldman, M. S. (2010). Explicit and implicit measures of expectancy and related alcohol cognitions: A meta-analytic comparison. Psychology of Addictive Behaviors, 24(1), 13-25. https://doi.org/10.1037/a0016556.

Reich, S., Schneider, F. M., \& Heling, L. (2018). Zero likes-symbolic interactions and need satisfaction online. Computers in Human Behavior, 80, 97-102. https://doi.org/10.1016/j.chb.2017.10.043.

Rudd, N. A., \& Lennon, S. J. (2000). Body image and appearancemanagement behaviors in college women. Clothing and Textiles Research Journal, 18(3), 152-162. https://doi.org/10.1177/ 0887302 X0001800304.

Rutledge, P. B. (2013). \#Selfies: Narcissism or self-exploration?, Psychology Today, April 18. Retrieved December 14, 2019, from: https://www.psychologytoday.com/blog/positively-media/201304/ selfies-narcissism-or-self-exploration

Sorokowska, A., Oleszkiewicz, A., Frackowiak, T., Pisanski, K., Chmiel, A., \& Sorokowski, P. (2016). Selfies and personality: Who posts self-portrait photographs? Personality and Individual Differences, 90, 119-123. https://doi.org/10.1016/j.paid.2015.10.037.

Sung, Y., Lee, J. A., Kim, E., \& Choi, S. M. (2016). Why we post selfies: Understanding motivations for posting pictures of oneself. Personality and Individual Differences, 97, 260-265. https://doi. org/10.1016/j.paid.2016.03.032.

Taylor, S. H., Hinck, A. S., \& Lim, H. (2017). An experimental test of how selfies change social judgments on Facebook. Cyberpsychology, Behavior and Social Networking, 20(10), 610 614. https://doi.org/10.1089/cyber.2016.0759.

Terán, L., Yan, K., \& Aubrey, J. S. (2019). "But first let me take a selfie": US adolescent girls' selfie activities, self-objectification, imaginary audience beliefs, and appearance concerns. Journal of Children and Media, 1-18 Epub ahead of print. https://www.tandfonline.com/loi/ rchm20.

Toma, C. L. (2013). Feeling better but doing worse: Effects of Facebook self-presentation on implicit self-esteem and cognitive task performance. Media Psychology, 16(2), 199-220. https://doi.org/10.1080/ 15213269.2012 .762189

Turel, O., \& Serenko, A. (2012). The benefits and dangers of enjoyment with social networking websites. European Journal of Information Systems, 21(5), 512-528. https://doi.org/10.1057/ejis.2012.1.

Van de Vijver, F. J., \& Poortinga, Y. H. (2004). Conceptual and methodological issues in adapting tests. In Adapting educational and psychological tests for cross-cultural assessment (pp. 51-76). London: Lawrence Erlbaum Associates, Publishers.

Vandenbosch, L., \& Eggermont, S. (2013). Sexualization of adolescent boys: Media exposure and boys' internalization of appearance ideals, self-objectification, and body surveillance. Men and Masculinities, 16(3), 283-306. https://doi.org/10.1177/ 1097184 X13477866.

Veldhuis, J., Alleva, J. M., Bij de Vaate, A. J., Keijer, M., \& Konijn, E. A. (2020). Me, my selfie, and I: The relations between selfie behaviors, body image, self-objectification, and self-esteem in young women. Psychology of Popular Media Culture. Epub ahead of print. https:// doi.org/10.1037/ppm0000206

Wang, Y., Xie, X., Fardouly, J., Vartanian, L. R., \& Lei, L. (2019). The longitudinal and reciprocal relationships between selfie-related behaviors and self-objectification and appearance concerns among adolescents. New Media \& Society, 1461444819894346, 1-22. https:// doi.org/10.1177/1461444819894346.

We Are Social (2021) Digital in 2020 global overview. Retrieved February 08, 2020, from: https://wearesocial.com/digital-2021

Webb, H. J., Zimmer-Gembeck, M. J., Waters, A. M., Farrell, L. J., Nesdale, D., \& Downey, G. (2017). "Pretty pressure" from peers, parents, and the media: A longitudinal study of appearance-based rejection sensitivity. Journal of Research on Adolescence, 27(4), 718-735. https://doi.org/10.1111/jora.12310.

Yau, J. C., \& Reich, S. M. (2019). "It's just a lot of work": Adolescents' self-presentation norms and practices on Facebook and Instagram. Journal of Research on Adolescence, 29(1), 196-209. https://doi. org/10.1111/jora.12376.

Zhao, S., Grasmuck, S., \& Martin, J. (2008). Identity construction on Facebook: Digital empowerment in anchored relationships. Computers in Human Behavior, 24(5), 1816-1836. https://doi.org/ 10.1016/j.chb.2008.02.012.

Zheng, D., Ni, X. L., \& Luo, Y. J. (2019). Selfie posting on social networking sites and female adolescents' self-objectification: The moderating role of imaginary audience ideation. Sex Roles, 80(5-6), 325-331. https://doi.org/10.1007/s11199-018-0937-1.

Publisher's Note Springer Nature remains neutral with regard to jurisdictional claims in published maps and institutional affiliations. 